\title{
A simple, fast and low-cost method for in situ monitoring of topographical changes and wear rate of a complex tribo-system under mixed lubrication
}

\author{
B. Meylan ${ }^{\text {a }}$, P. Dogan ${ }^{\text {b }}$, D. Sage ${ }^{\text {b }}$, K. Wasmer ${ }^{\text {a,* }}$ \\ ${ }^{a}$ Empa, Swiss Laboratories for Materials Science \& Technology, Laboratory for Advanced Materials Processing, Feuerwerkerstrasse 39, CH-3602 Thun, \\ Switzerland \\ ${ }^{\mathrm{b}}$ Ecole Polytechnique Fédérale de Lausanne (EPFL), Biomedical Imaging Group (BIG), CH-1015 Lausanne, Switzerland
}

\section{A R T I C L E I N F O}

\section{Article history:}

Received 19 February 2016

Received in revised form

4 May 2016

Accepted 6 June 2016

Available online 11 June 2016

Keywords:

Cast iron

Surface topography

Optical microscopy

Profilometry

Image analysis

\begin{abstract}
A B S T R A C T
This contribution presents a simple, fast, and low-cost method to track in situ and in real time the evolution of the surface topography. The method combines an optical method (collimated light) with image analysis. The method was validated using a complex tribo-system; a reciprocal sliding of a rough cast iron counter-piece under mixed lubrication.

We demonstrated that the optical method is well suited to observe the evolution of the contact areas during sliding. We also proved that the contact area occurs on the highest peaks of the surface roughness. Finally, we estimated the wear rate by combining the information of the contact area and the Abbott-Firestone curve obtained by profilometry. The wear rate was found to be 40 times higher in the early stage of sliding as compared to the steady-state. The running-in of this particular system was found to be approximately $10 \mathrm{~h}$.

In addition to be simple, fast and low-cost, the proposed method has other advantages. It is adaptable for real industrial tests conditions. The fast data analysis allows the wear rate of a tribo-system being determined in real-time. This method characterise the real contact areas of the observed piece, which is difficult, if not impossible, to obtain by profilometric observation alone.
\end{abstract}

(c) 2016 Elsevier B.V. All rights reserved.

\section{Introduction}

In many systems operating at high load or low speed, the oil film thickness is approximately equal to the roughness of the surfaces [1]. Direct contact of the asperities is therefore inevitable, especially during the running-in of the sliding of a tribo-pair. Under these conditions, the system is described as under mixed lubrication where the load is sustained by both the lubricant and solid-solid contacts. During sliding, the higher asperities in contact are worn out and this leads to an increase of the surface area in direct contact [2-5]. This increase of contact area causes the load to be sustained by a larger surface so that the local pressure decreases, resulting into a decrease of the wear rate with time. It is known that the wear rate is not constant and is usually significantly higher in the early stages of a sliding process. Consequently, a method to measure the wear rate constantly during a process is essential, not only to detect any abnormal wear rate at any stages of the process but also, to get a fundamental understanding of the wear mechanism. This enables

\footnotetext{
* Corresponding author. Fax: +4158765 6990.

E-mail address: kilian.wasmer@empa.ch (K. Wasmer).
}

the development of a more precise wear model and also to better predict the lifetime of a given system.

Some studies $[1,6-10]$ have already highlighted the importance of measuring the wear rate continuously and in situ during the process. However, in most studies, the tribo-system is simplified to allow in situ measurements $[7,8]$. Such simplifications are ideal to investigate the fundamental behaviour of a given tribo-pair from a material perspective. In contrast, it is difficult to transpose these results to real industrial cases. Another method, the radionuclide technique allows measuring very accurately the wear rate and can be adapted to system with very low wear rate $[9,10]$. However, this method still requires heavy equipment and big investment to detect the radiation emitted from the wear debris of activated material, even though recent progress of this technique has reduced the need for heavy shielding [9]. Moreover, this method is adapted to measure the wear rate but does not give information on the local change of the surface topography. To overcome these difficulties, special optical methods combining speckle and scattering phenomena coupled with image analysis were used to calculate the roughness on a moving surface $[1,6]$. Other studies [11-13] have exploited rapid methods, consisting of a visual monitoring system combined with a known illumination and 
image analysis to assess the surface roughness but without directly monitoring a tribological process. The present study combines an optical system with image analysis techniques to evaluate the evolution of the contact area with sliding time. The custom made setup allows following the evolution of the surface with time and to monitor the local changes of the surface topography. Based on this information, it is possible to derive the wear rate as the test is ongoing. This system is particularly useful during the running-in stage, when the wear rate and the risk of seizure is the most important.

\section{Experimental method}

\subsection{Tribological test}

It is important to mention that the method developed in this contribution is very flexible and can be easily adapted to various tribologcial systems. In this work, the method was developed and validated for one test based on a specific industrial application. To do so, a custom made setup was used to perform reciprocal sliding of a half journal bearing and it is presented in Fig. 1. A variable load was applied during each cycle according to Fig. 2. At the beginning of the movement, the load was fixed to a minimum value; a parameter that could be adjusted between $1 \mathrm{kN}$ and $20 \mathrm{kN}$. Near the end of the rotation of the axis $\left(50^{\circ}\right)$, the load increased rapidly towards its maximum value which can be set up to $250 \mathrm{kN}$ as shown in Fig. 2 . The maximum load was reached at the end of the rotation $\left(50^{\circ}\right)$ when the linear speed at contact is $0 \mathrm{~m} / \mathrm{s}$. After, the axis was rotated back to its initial position while the load decreased back to its minimum value. The number of cycles per hour (cycle rate) was also adjustable and can vary between 3000 and 9500 cycles/h. During the complete duration of a test, an ISO-VG 220 oil was poured in the gap between the two pieces at a rate of $1.3 \mathrm{dL} / \mathrm{min}$ (See Fig. 1c).

To avoid catastrophic failure at the beginning of the test, a special loading procedure was carried out during the first $8 \mathrm{~h}$ of sliding. During this time, the tribo-pair follows a procedure during which the load and the cycle rate increase progressively step-bystep. The details of the initial loading procedure carried out are given in Fig. 3. For the first eight hours of sliding, the minimum load was kept at $1 \mathrm{kN}$ and the maximum load was gradually increased from $60 \mathrm{kN}$ to $250 \mathrm{kN}$. Simultaneously, the cycle rate was increased from 4000 cycles/h to 9500 cycles/h. After the loading procedure $(8 \mathrm{~h})$, the maximum load and cycle rate were kept at their maximum values of $250 \mathrm{kN}$ and $9500 \mathrm{cycles} / \mathrm{h}$, respectively, whereas the minimum load was increased and kept constant to $4 \mathrm{kN}$ up to $40 \mathrm{~h}$. The machine was stopped after $4.5,8$,

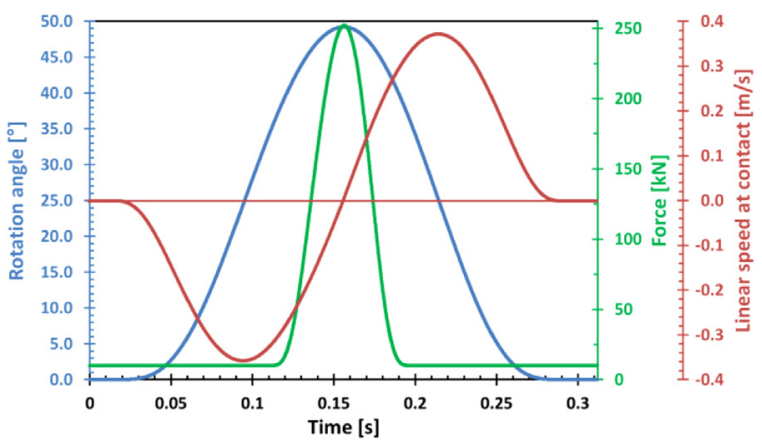

Fig. 2. Evolution of the rotation angle, load and linear speed during one cycle for a maximum load of $250 \mathrm{kN}$ and cycle rate of $9500 \mathrm{cycles} / \mathrm{h}$.

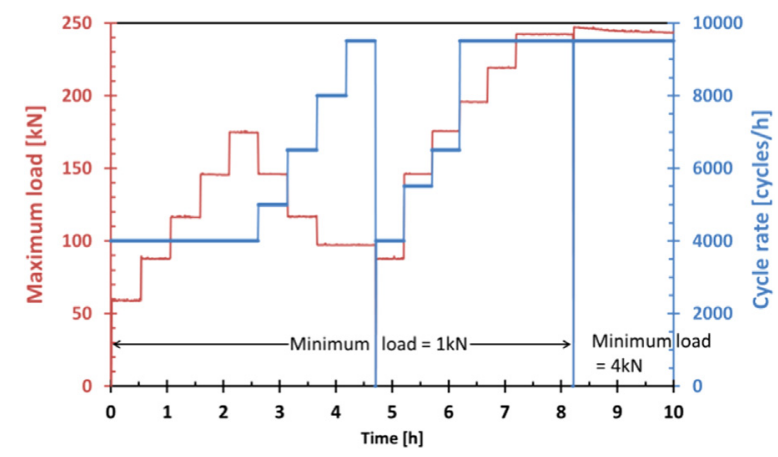

Fig. 3. Load and cycle rate steps used during the loading procedure (the first $8 \mathrm{~h}$ ). After, the load and cycle rate were kept at $250 \mathrm{kN}$ and 9500 cycles/h, respectively, but the minimum load is increased to $4 \mathrm{kN}$. The sample was unmounted and checked after 4.5, 8, 22 and $36 \mathrm{~h}$.

Table 1

Chemical composition of the cast iron sample and the steel axis (wt\%).

\begin{tabular}{cccccccccc}
\hline & $\mathrm{C}$ & $\mathrm{Mn}$ & $\mathrm{Si}$ & $\mathrm{P}$ & $\mathrm{S}$ & $\mathrm{Cu}$ & $\mathrm{Cr}$ & $\mathrm{Mo}$ & $\mathrm{Fe}$ \\
\hline $\begin{array}{c}\text { Grey cast } \\
\text { iron }\end{array}$ & 2.890 & 0.940 & 1.470 & 0.036 & 0.059 & 1.000 & - & - & Balance \\
$\begin{array}{c}42 \mathrm{CrMo} 4 \\
\text { steel }\end{array}$ & 0.400 & 0.750 & 0.330 & 0.035 & 0.028 & - & 1.010 & 0.160 & Balance \\
\hline
\end{tabular}

22 and $36 \mathrm{~h}$. These stops were necessary to change the settings and to allow for ex situ observations of the surface. Each stop was sufficiently long to cool the machine and the oil down to their initial temperatures before restarting the test.
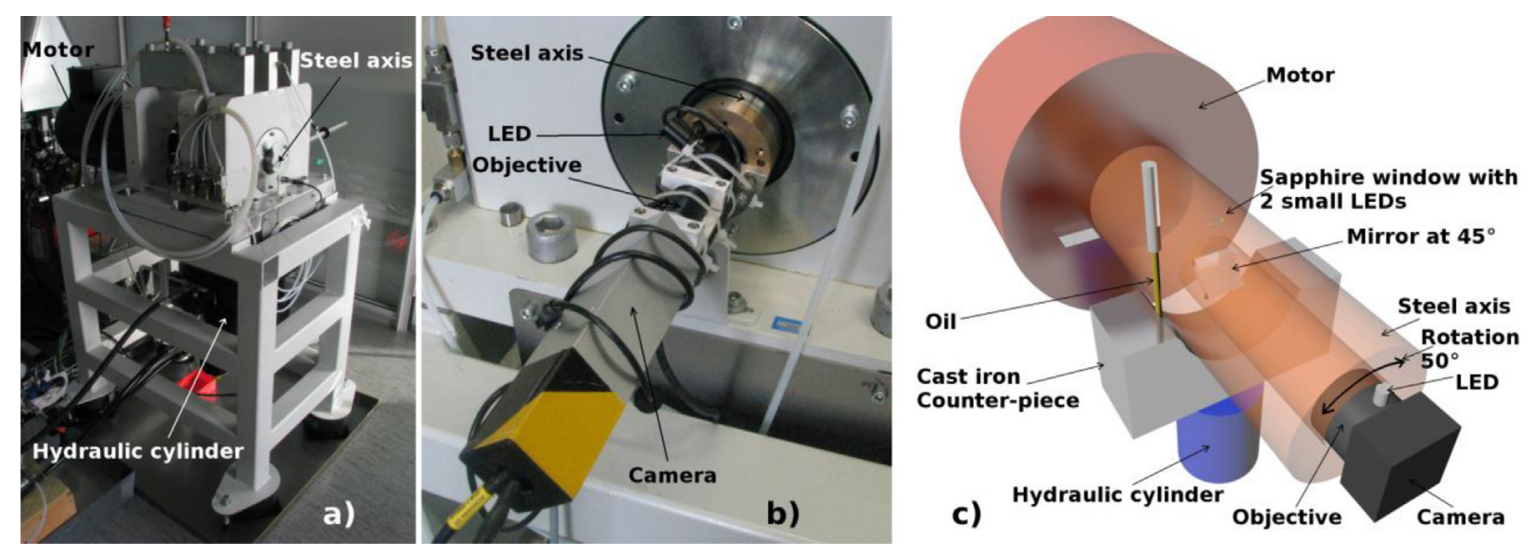

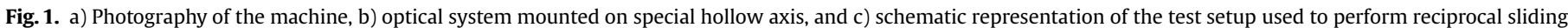
of a steel axis against a cast iron counter-piece. 


\subsection{Material and geometry of the work pieces}

The steel axe of the tribo-system had a diameter of $65 \mathrm{~mm}$ and was made of surface-hardened $42 \mathrm{CrMoS} 4$ steel with the chemical composition given in Table 1 . The surface roughness $(\mathrm{Sa})$ was $0.3 \mu \mathrm{m}$. The counter-piece was in grey cast iron (composition given in Table 1) with an inner diameter of $65.14 \mathrm{~mm}$. Moreover, two oil grooves were machined perpendicular to the sliding direction as illustrated in Fig. 4. For the grey cast iron workpiece, the surface roughness $(\mathrm{Sa})$ of the contact region was $0.9 \pm 0.1 \mu \mathrm{m}$.

\subsection{Ex situ characterisation of the surface}

As previously mentioned, the cast iron counter-piece was dismounted after 4.5, 8, 22 and $36 \mathrm{~h}$ for ex situ observation. To start with, a visual observation of the surface was made to insure that no severe wear had occurred during testing. Secondly, the surface was cleaned with acetone followed by ethanol in an ultrasonic bath. Then, the surface topography was measured with a white light profilometer Altisurf 500 from Altimet, equipped with an optical pen OP300WM from Stil SA. The given specifications are a maximum vertical range of $300 \mu \mathrm{m}$ and an axial resolution of $10 \mathrm{~nm}$. Surfaces of 8 by $8 \mathrm{~mm}$ were scanned with a lateral step of $5 \mu \mathrm{m}$. Finally, the counter-piece was mounted back, to all intents and purposes, in their original test setup position. Despite all the precautions taken, it is impossible to guarantee that the counterpiece was placed exactly at its original position and some discrepancy between the steps may be observed.

To compare the observations made ex situ with the ones made in situ presented in the next section, a circular indentation was made at the centre of the cast iron piece as a reference point using a Brinell indentation. This indentation induced some plastic deformation creating a ridge around the imprint higher than the initial surface. It was expected that this ridge will be worn out significantly, especially during the running-in.

\subsection{In situ observation of the cast iron counter-piece surface}

To observe the surface of the cast iron counter-piece without having to stop the machine and dismount the system, the tribo-test was performed with a custom-made hollow axis (see Figs. 1 and 4). The axis comprised a small sapphire window at a position that was matched to the centre of the cast iron counter-piece. Below this window, in the middle of the axis, a $45^{\circ}$ mirror was installed to project the images to the optics and into the camera fixed at the end of the steel axis. The optical system has a magnification of 4 times and each picture cover approximately a surface of $5 \mathrm{~mm}^{2}$ ( 2.5 by $2 \mathrm{~mm}$ ). Two lightning systems were installed to observe the surface. Firstly, two small LEDs were placed at both sides of the window with a $45^{\circ}$ angle to the surface and thereafter referred to the $45^{\circ}$ LED illumination. Secondly, a collimated incident light from the side of the camera was forwarded normal to the surface and thereafter referred to the normal collimated illumination. During the triboexperiment, the sapphire window did not face the cast iron piece not to influence the test (see Fig. 4a). But, at given regular intervals, the axis was rotated so that the window allows pictures of the cast iron surface to be taken (see Fig. 4b). To observe the total length of the contact area over a $2.5 \mathrm{~mm}$ width, a series of 100 pictures was taken with both lightning systems. To acquire the pictures, the axis is rotated by small steps, every $2 \mathrm{~s}$, at a constant load of $1 \mathrm{kN}$. For the first $8 \mathrm{~h}$ of the test, it was decided to take a series of pictures every $10 \mathrm{~min}$. Afterwards, the series of pictures were taken every hour. This was chosen to consider the higher wear rate expected at the beginning of the test.

\subsection{Image analysis of the pictures taken in situ}

A large amount of images (16,000 per sample for a $40 \mathrm{~h}$ test) was acquired for each sample. To organise, process, and visualise the recorded data, a set of software image-analysis tools have been specially written as Java plugins for the open-source platform Image [14]. This set of plugins of this contribution are made freely available at: http://bigwww.epfl.ch/algorithms/tribology/. This plug-in is able to order and group the images taking into account their corresponding cycles as a pre-processing step, using the timestamps of the pictures. For time difference of $2 \mathrm{~s}$ between two consecutive images, they are grouped in the same folder. When a longer time is detected, which indicates the start of another cycle, a new folder is created where the following images are grouped. Once the pictures are grouped and ordered within the folders, the panoramic reconstruction of the surface can be made for each cycle by stitching individual images (e.g. Figs. $7 \mathrm{~b}$ and $8 \mathrm{a}$ ). The stitching requires a registration step to compensate for the small movements of the camera. The registration is automatically performed using only the image content. The ImageJ plugin TurboReg [15] was used for the registration. In this way, the panoramic image of the surface is obtained starting from the first image and registering the rest in a progressive way. The panoramic image is very useful to compare the selected region at different times (cycles) under a chosen lightning condition by getting the corresponding image stack by the plug-in. Alternatively, the plug-in also provides the image stack to compare the selected region with the two different lightning conditions. During the image capture, some bubbles in the oil were visible between the sapphire window and the cast-iron counterpiece which were occluding the surface partially. The plug-in is able to remove these bubbles by an appropriate temporal filter using the information from the previous and following cycles. Moreover, the plug-in allows estimating the contact area and its evolution with time by evaluating the pixels values.

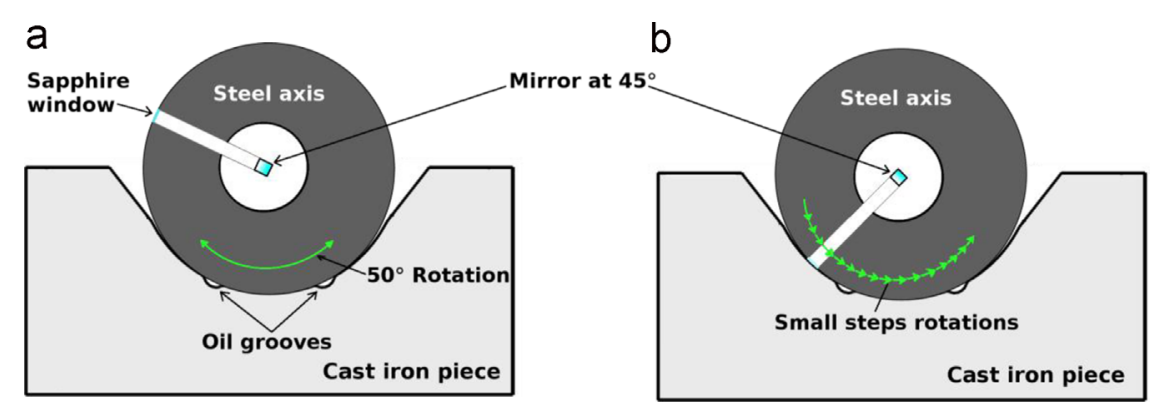

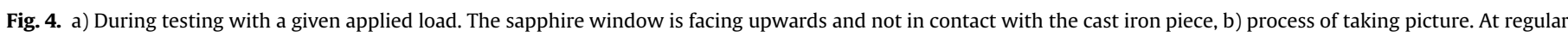

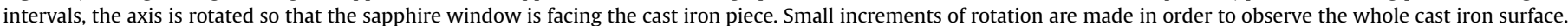
At each rotational step, a pause of $2 \mathrm{~s}$ is made to take one picture with each different lightning system. 

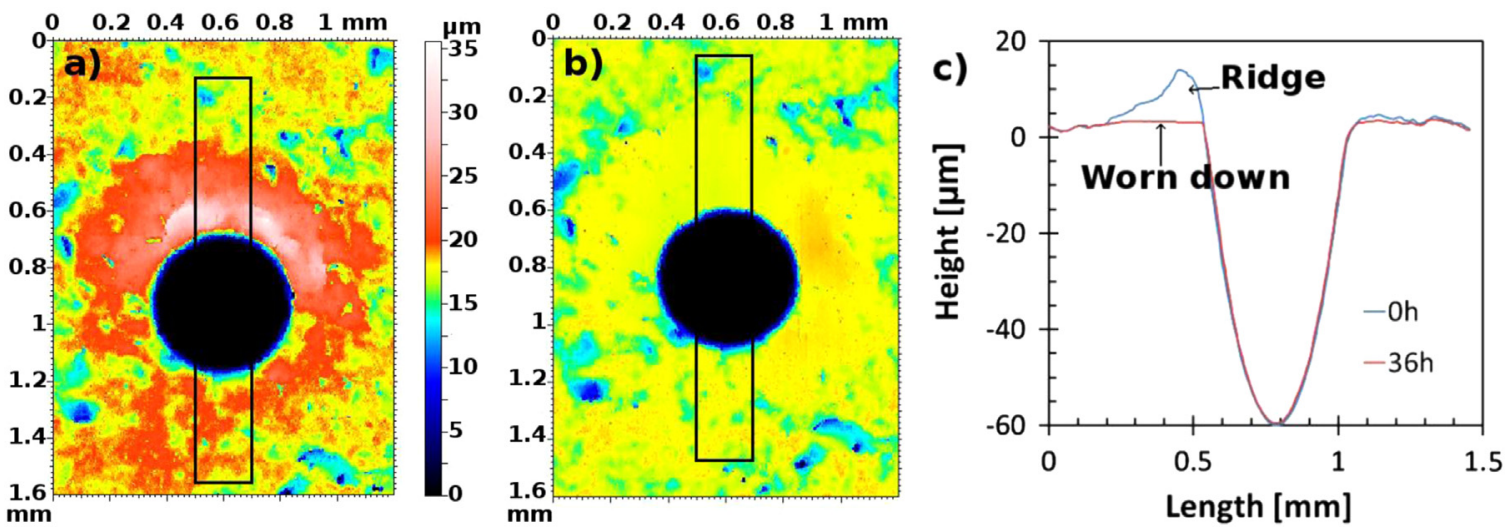

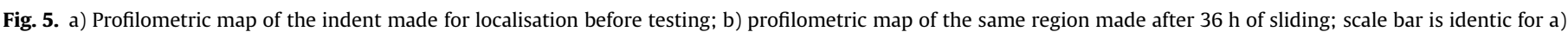
and $b$ ). c) Average profiles made in the black box region of a) and b).
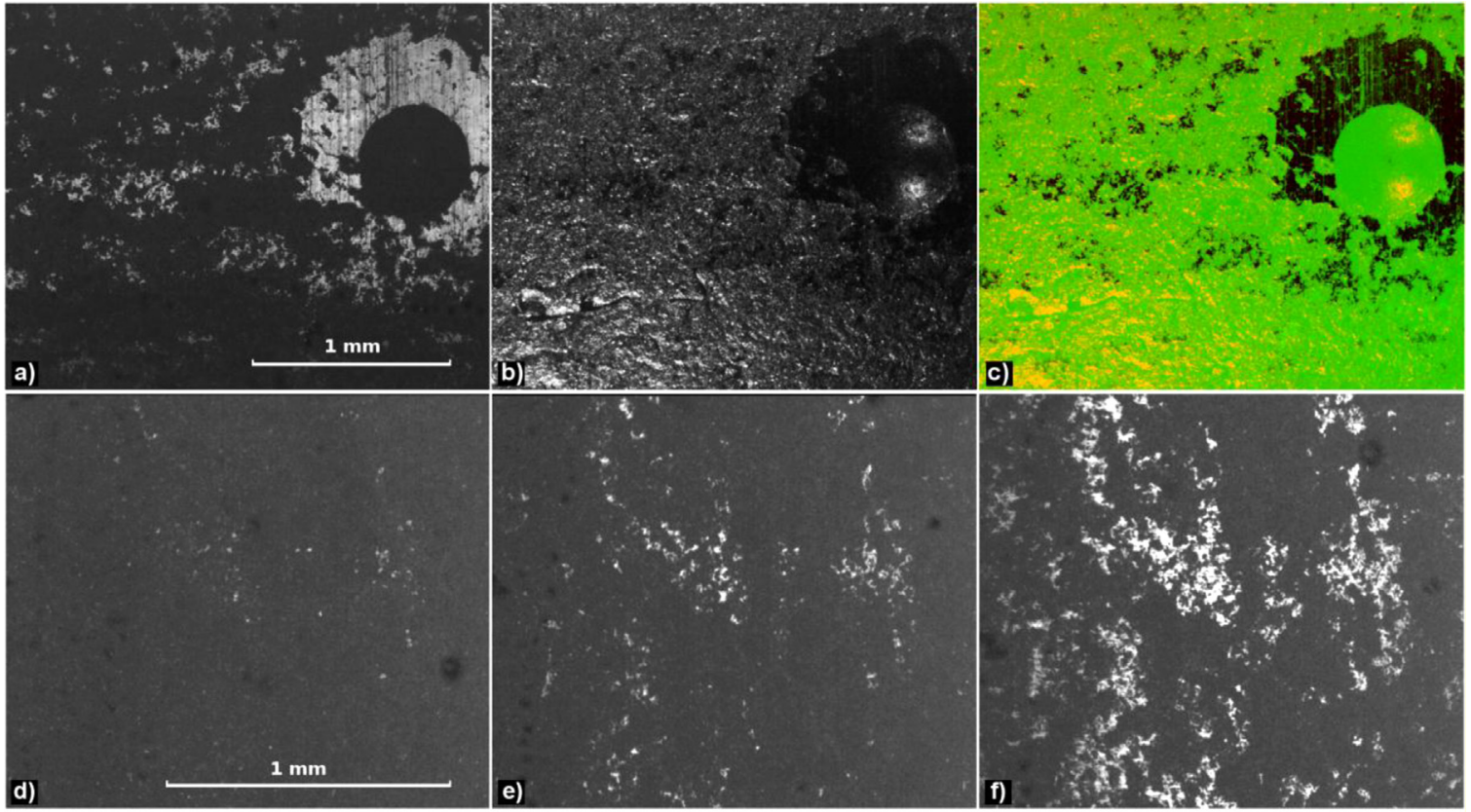

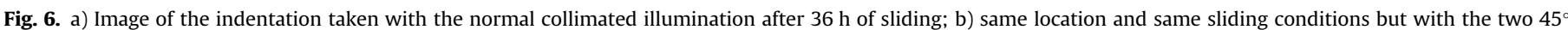

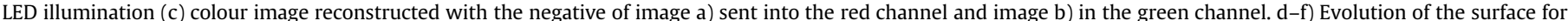

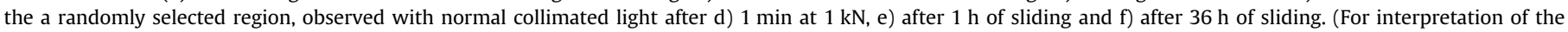
references to color in this figure legend, the reader is referred to the web version of this article).

\section{Results and discussion}

\subsection{Proof of concept to determine flat regions}

To measure the wear rate, it is necessary to observe the changes in the surface topography and in particular of flat regions. Fig. 5 presents profilometric maps of the indent used for the localisation before testing (Fig. 5a) and after $36 \mathrm{~h}$ (Fig. 5b). It also includes an average profile made from the black box regions. Fig. 5a and $c$ shows clearly a ridge formed as a result of the large plastic deformation induced by the indentation. This ridge is worn down and polished during the first $36 \mathrm{~h}$ of the test and evidence of this is in Fig. 5c (when comparing both profiles).

Fig. 6 shows two typical images taken with the developed optical system at the same location as in Fig. 5 but during the tribological experiment. Both images were taken, for comparison purpose, near the indentation on the cast iron after $36 \mathrm{~h}$ of sliding. Fig. 6a was obtained using the normal collimated illumination whereas Fig. $6 \mathrm{~b}$ the $45^{\circ}$ LED illumination.
In Fig. 6a, the black round spot on the right hand side of the picture corresponds to the indentation and is surrounded by a large bright area. When comparing Figs. $5 \mathrm{~b}$ and $6 \mathrm{a}$, it can be concluded that this area corresponds to worn out and polished ridge. This is not surprising as it was expected that with the normal collimated illumination, the flat parts reflect back the most light to the camera and so appear in light grey.

In Fig. 6b, the bright regions correspond to surfaces with a slope of approximately $\pm 22.5^{\circ}$ so that the light can be reflected from the two small LED lights to the camera. In this case, the flat area is black as the light coming at $45^{\circ}$ is reflected with the same angle and thus not in direction of the camera (at $90^{\circ}$ ). This illumination allows observing the regions appearing in black with the normal collimated light. Consequently, it increases the amount of information collected about the topography of the valleys of the surface.

To get a better representation of the contact area (the flat area), Fig. $6 a$ and $b$ were combined together. Actually, to represent the flat area in black, the negative of Fig. 6a was combined with Fig. $6 \mathbf{b}$ to create 
Fig. 6c. The images are used on different colour channels to build an artificial colour image (Fig. 6c). In this image, the flat areas appear clearly in black as the negative of Fig. 6a is taken and are already in black in Fig. $6 \mathrm{~b}$. The bright regions in Fig. $6 \mathrm{~b}$ and the dark regions of Fig. 6a appear in orange and green, respectively. From Fig. $6 c$, although the $45^{\circ}$ LED illumination brings some information about the topography of the valleys of the surface, it does not help much for the recognition of the contact areas. Hence, only the normal collimated light is considered in the subsequent results.

An example of the evolution of the surface observed with the collimated light is given in Fig. $6 \mathrm{~d}-\mathrm{f}$. The same region of the surface was observed at the start of the experiment, during the early stage of running-in and during the steady-state. Fig. 6d was taken with the minimum load of $1 \mathrm{kN}$ was applied for approximately $1 \mathrm{~min}$. The image is mostly dark grey due to the rough surface of the sample from which almost no light is reflected in the direction of the camera. In this image, only a few bright dots are visible and they correspond to the top of the highest asperities that are in contact at this small load. It is interesting to observe that these small bright dots evolve and start to become larger when the sliding time increases and evidence of this is in Fig. Ge and $\mathrm{f}$. The number of contact regions also rises as the test progresses and more asperities begin to be in contact. The registration of the pictures proved also that the bright dots observed in the reference Fig. 6d, superposed perfectly with the largest bright regions in Fig. 6e and $\mathrm{f}$.

\subsection{Validation of the optical system}

In order to validate our in situ measurement system and improve confidence in it, a comparison of a large area of the cast iron counter-piece ( 2 by $8 \mathrm{~mm}$ ) was made between a profilometric map (after form removal) (Fig. 7a) and a panorama of images taken with the normal collimated light (Fig. 7b), both realised after $40 \mathrm{~h}$ of sliding. For better comparison, an average profile of Fig. 7a and a light intensity profile of Fig. $7 \mathrm{~b}$ are shown in Fig. 7c.

In Fig. 7a, the surface height is given by grey levels, the lighter greys indicating the higher surfaces. The highest peaks (light grey regions in Fig. $7 \mathrm{a}$ ) are around $2 \mu \mathrm{m}$ and $3 \mu \mathrm{m}$ above the average height set as $0 \mu \mathrm{m}$. In contrast, the deepest valleys (dark grey regions in Fig. 7a) are $2 \mu \mathrm{m}$ and $3 \mu \mathrm{m}$ below the average height. Also, in Fig. 7a, vertical regions of relatively high surface with peaks higher than $1 \mu \mathrm{m}$ above the average are visible and are marked in red in the scale bar $(0-1.2 \mathrm{~mm} ; 3-5.5 \mathrm{~mm}$; and $7.2-8 \mathrm{~mm})$. In

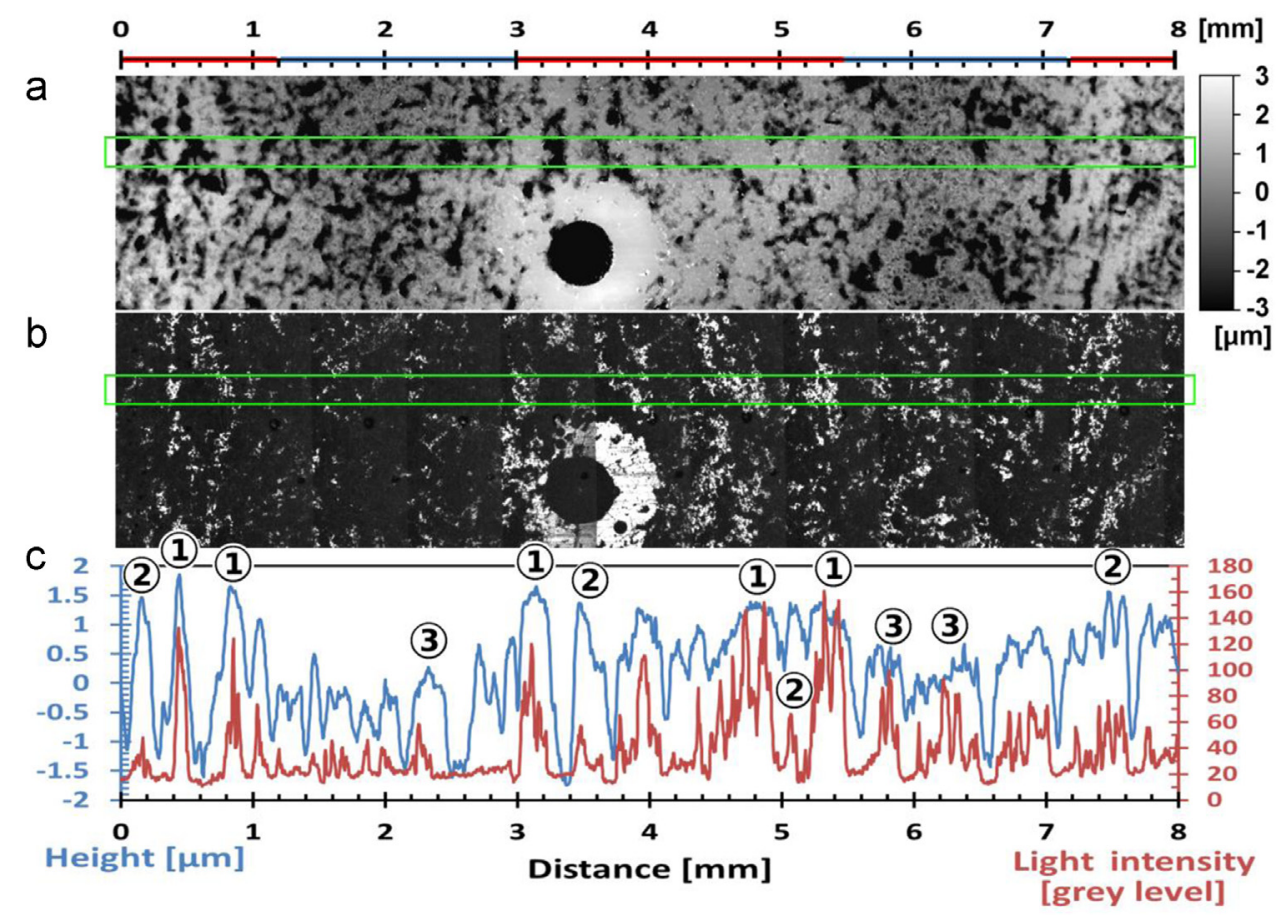

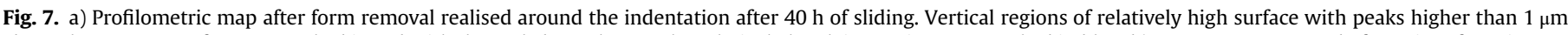

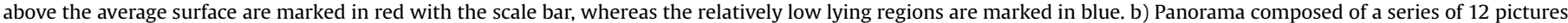

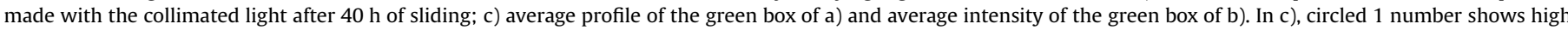

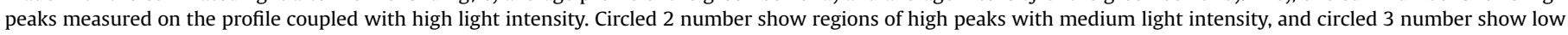
peaks with medium light intensity. (For interpretation of the references to color in this figure legend, the reader is referred to the web version of this article).

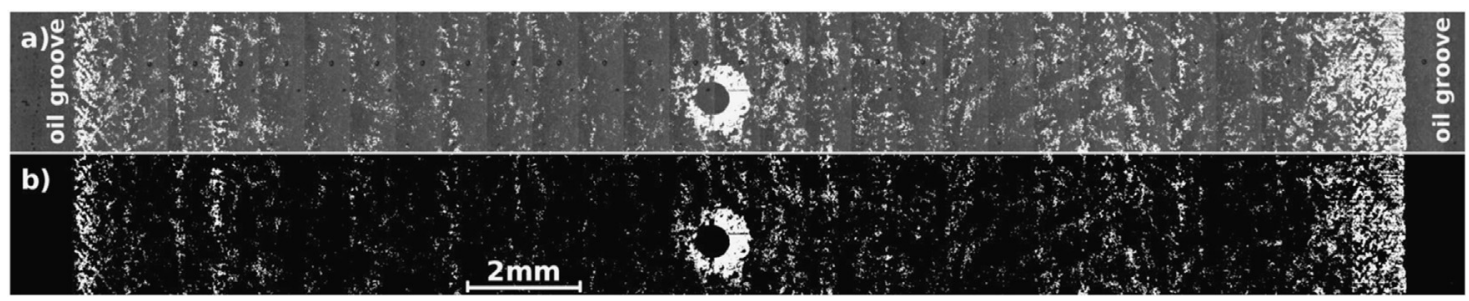

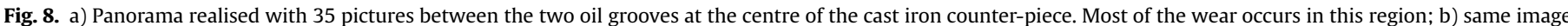
after thresholding in order to separate the contact area (in white) from the non-contact area (in black). 
contrast, some relatively low lying regions can be seen and are marked in blue $(1.2-3 \mathrm{~mm}$ and $5.5-7.2 \mathrm{~mm}$ ). These regions are probably created during the machining. In the following discussion, the peaks present in the high area are referred as high peak whereas peaks in low lying areas are referred as low peaks.

Fig. 7b presents a panorama of 12 successive pictures taken with the normal collimated light. The registration was performed on Fig. 7b so that each point of the figure corresponds to the same point in Fig. 7a. Obviously, all bright regions in Fig. 7b coincide to light grey regions in Fig. 7a. This is not surprising as the highest peaks are expected to be the contact regions where the solid-solid contact occurs first.

A more precise comparison is presented in Fig. 7c where the average profile (in blue) obtained from the green box of Fig. 7a is compared to the average grey level light intensity (in red) measured in the same region of Fig. 7b. Obviously, peaks on the light intensity curve represent regions of the contact area. Actually, high light intensity peaks (average light intensity $\geq 100$ ) are produced when the contact area is almost equal to the width of the green box and are marked with a circle 1 . Medium light intensity peaks are produce when the contact area is smaller than the width of the green box and are marked with circles 2 and 3 .

A careful comparison of Fig. 7a and b shows that each local peak of light intensity (Fig. 7b) has a corresponding peak on the surface profile (Fig. 7a) as seen in Fig. 7c. The opposite is, however, not always true as some local peaks on the profile do not produce automatically a contact. This is particularly the case when the local peaks are surrounded by higher peaks. In addition, most of the high peaks in the profile produce also high light intensity peaks as shown with the circles 1 in Fig. 7c. This is easily explained by the fact that these high peaks are subjected to the highest local pressure at the beginning of the running-in and so to the highest wear which produces the largest area of contact as the summit of the peaks are worn out. It is also seen that some high peaks in the profile coincide with medium peaks of light intensity and evidence of this is shown with the circles 2 in Fig. 7c. The reason is that, as already mentioned, these peaks are surrounded by higher peaks on which the local pressures are higher. Consequently, the local pressure on these slightly lower peaks is smaller leading to less wear and a smaller contact area. Interestingly, it appears from the profile that the last peak with a circle 2 , on the right hand side of the figure, is not surrounded by higher peaks in the horizontal direction. But, a close look at Fig. 7a and $b$ shows that large bright areas, indicating high peaks, are situated just above and below the green region used for the calculation of the profile. Although, these regions were not measured for the profile calculation, they still influenced the local pressure on this peak. It confirms that the distribution of the contact areas is complex and that the whole surface has to be taken in consideration for a proper analysis. Finally, some low lying peaks of the profile (Fig. 7a) can also, in some cases, results in a medium light intensity peak (Fig. 7b) and they are indicated in Fig. 7c by the circles 3. They are usually situated in regions where no higher peaks are present and these regions are indicated by the blue colour of the scale bar in Fig. $7 \mathrm{a}(1.2-3 \mathrm{~mm}$ and $5.5-7.2 \mathrm{~mm})$. One possible explanation is that these peaks are brought in contact due to the elastic deformation of the counter-piece during the experiment. This is well illustrated by the peak numbered 3 at around $2.3 \mathrm{~mm}$ from the left of the profile in Fig. 7c. Indeed, this profile peak is relatively low but is surrounded by a region of even lower height (blue region between $1.2 \mathrm{~mm}$ and $3.0 \mathrm{~mm}$ of the scale bar in Fig. 7a). Despite this relative low height when compared to the complete profile, regions of contact are still produced in this part as no higher peak is found nearby to sustain the pressure. This demonstrates that, despite the fact that the profilometric map gives more detailed information regarding the surface topography as compared to the optical system (especially for the valleys), it does not provide sufficient information about the contact area. Thus, it can be concluded that it is difficult, if not impossible, to estimate the real contact area from a profilometric map. In contrast, although the panoramic picture gives less information about the topography, it provides the real information about the peaks that are in contact during sliding. In other words, it allows tracking precisely where the wear takes place and which peaks are polished by the sliding. Therefore, it can be established that wear is not only function of the peak height but also of the distribution of the peaks around. Some relatively low lying peaks can still be pushed into contact by elastic deformation if no higher peaks are found in the vicinity. In the opposite, relatively high peaks can produce a relatively small amount of contact area if they are surrounded by higher peaks.

\subsection{Evolution of the contact area with time}

It has been demonstrated that the optical images taken in situ provide useful information about the contact regions. Moreover, it was shown that for this tribo-system, an increase of the contact area in the direction of sliding increases the likelihood to develop scuffing failure [16]. This demonstrates that it is of critical importance to monitor closely the contact area to estimate the risk of failure of this system. Therefore, panoramic images of the cast
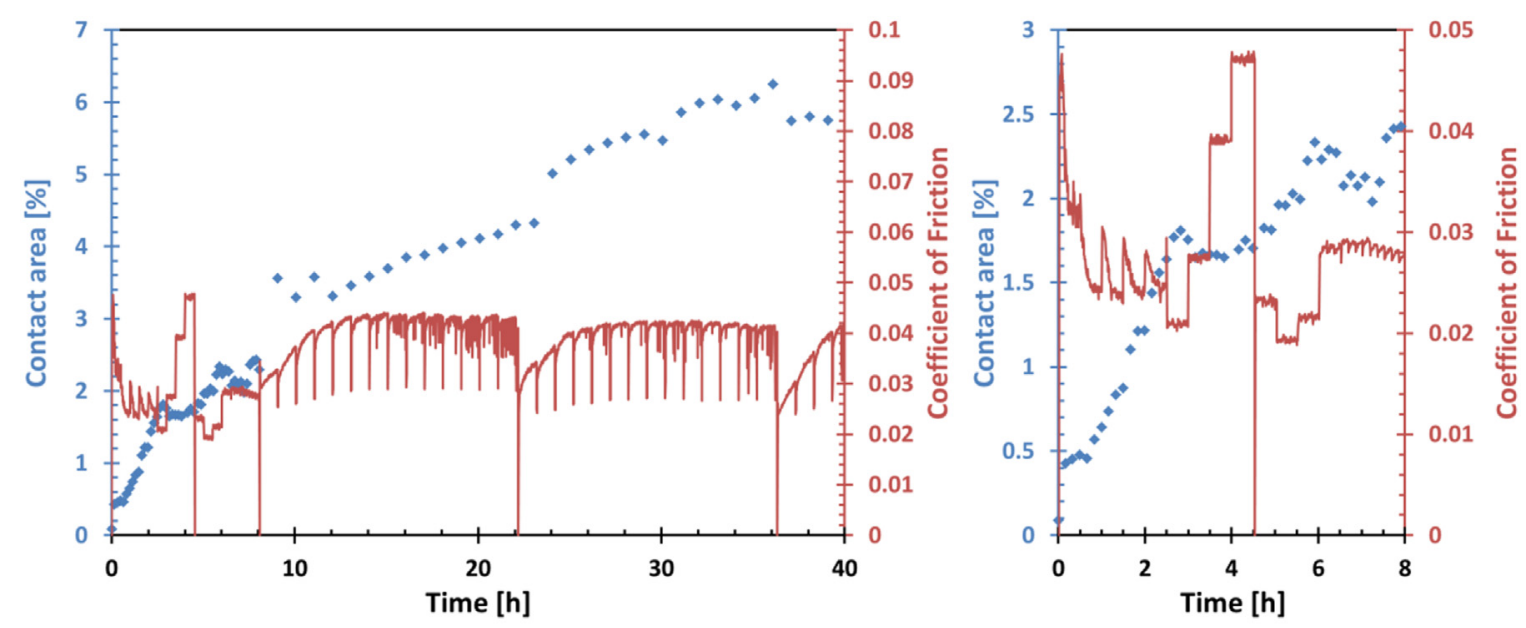

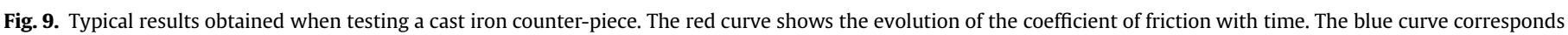

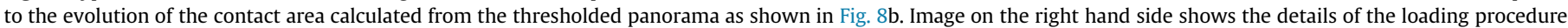
during the first $8 \mathrm{~h}$. (For interpretation of the references to color in this figure legend, the reader is referred to the web version of this article). 

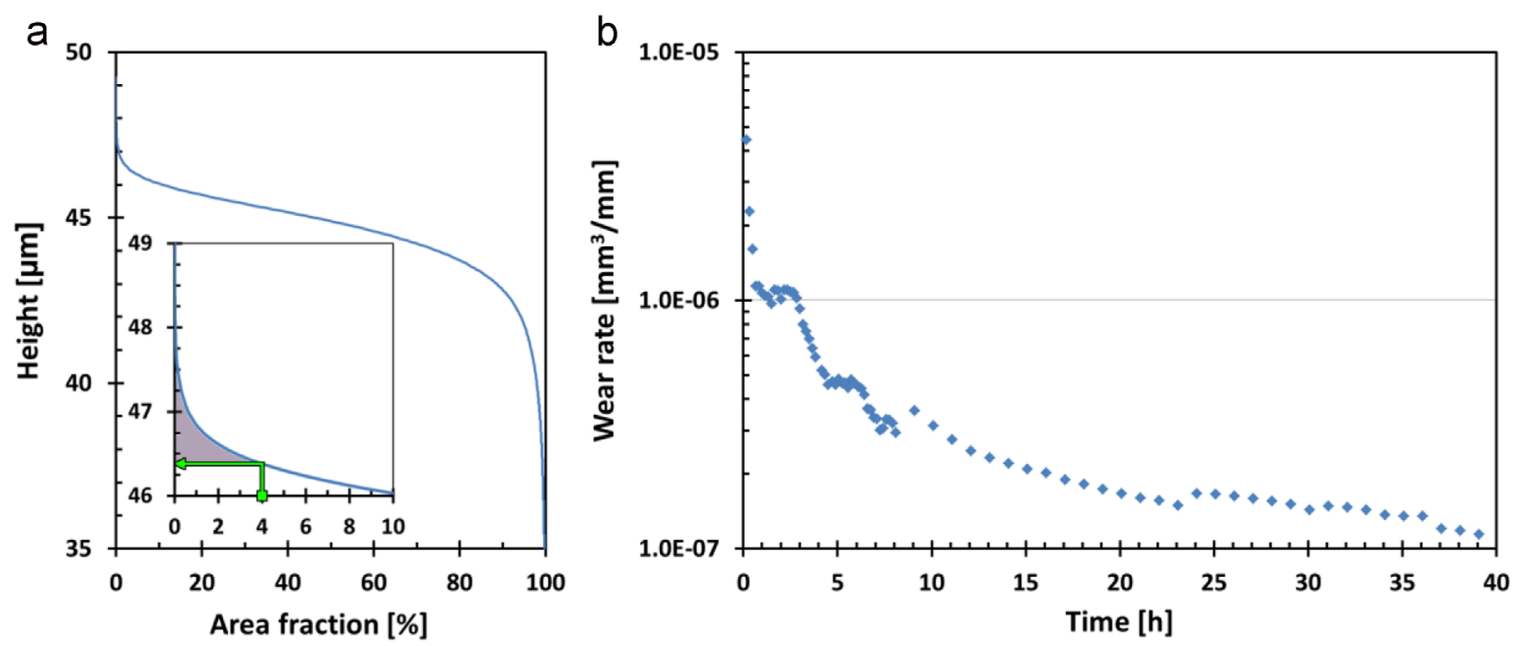

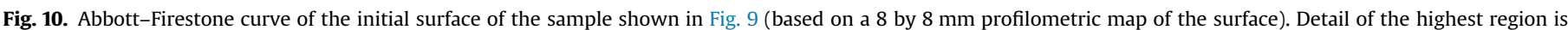

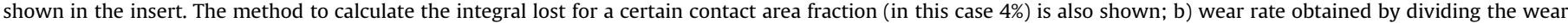
volume from Eq. (1) by the sliding distance.

iron counter-piece were created for each cycle of observation. To limit the computation time needed to build the panorama, only the centre region between the two oil grooves were considered. Each panorama contains 35 pictures and was cropped to have the oil grooves on both sides of the panorama. An example is shown in Fig. $8 \mathrm{a}$ after $40 \mathrm{~h}$ of sliding. So, each panorama compares the same region of the cast iron surface. Based on the experiments, the centre of the counter-piece is known to have most of the areas of contact and this was supported by FEM simulation (not shown here) to have the highest pressure. The pressure, for an applied load of $250 \mathrm{kN}$ in this region, varies between $110 \mathrm{MPa}$ and $170 \mathrm{MPa}$. In fact, the centre of the counter-piece is subjected to high load with the highest ones situated at the edge of the oil grooves.

Fig. $8 \mathrm{~b}$ is the same picture as Fig. $8 \mathrm{a}$ but after thresholding in order to keep only the brightest regions in white and the rest in black. The thresholding was performed using the automatic algorithm proposed by Ridler and Calvard [17] and implemented in ImageJ. On these pictures taken after $40 \mathrm{~h}$ of sliding, many white regions representing the contact areas are visible close to the two oil channels. These results confirm the FEM calculations indicating that the pressure is the highest directly next to the oil groove due to stress concentration induced by the grooves. Also, as already explained, the indentation created a ridge in its neighbourhood which was worn out resulting in a large contact region, which is visible at the centre of Fig. 8.

Based on this panoramic image and thresholding, the contact area can be easily estimated. To do so, the white and black regions, in Fig. 8b, are assumed to be the contact area and non-contact area, respectively. Then, the percentage of the contact area (or the white pixels) can be calculated for each panorama at different times and their corresponding values are plotted in Fig. 9. As expected, the augmentation of the contact area is significant in the first hours of the running-in, especially during the steps when the load is increased. During the first $2.5 \mathrm{~h}$, the contact area increases more or less linearly from 0 to $2 \%$. In the same time, the coefficient of friction decreases significantly at each constant load until the load is increased for the next step of the loading procedure. This is in agreement with publications that report a decrease of both the roughness and the coefficient of friction during the running-in [15]. Indeed, in this contribution, the augmentation of bright areas, as shown previously, was related to an increase of flat smooth regions which are also the contact areas. Considering that the rest of the surface stays unchanged, an increase of contact areas leads to a decrease of the average roughness of the sample.

Between $2.5 \mathrm{~h}$ and $4.5 \mathrm{~h}$, it is interesting to note that the contact area stays more or less constant at $1.7 \%$ even when the load of the system is decreased (See Fig. 3). Afterwards, the contact area rises again when the load and the cycle rate are increased to their maximum values. The linear increase of the contact area between $4.5 \mathrm{~h}$ and $6 \mathrm{~h}$ is unexpected as the load, during this time, is still below the maximum load used during the first $4.5 \mathrm{~h}$. Also, this increase of contact area also does not correspond, as previously observed, with a decrease of the coefficient of friction. As the counter-piece was taken out of the test setup after $4.5 \mathrm{~h}$ for observation and profilometric measurement, it is believed that, despite all the efforts, the counter-piece was not replaced exactly at the same position and so new regions are pushed in contact with the axis. This explains certainly some of the unexpected large changes of contact area observed after other repositioning of the counter-piece at 8,22 or $36 \mathrm{~h}$. This highlights one of the major problems with ex situ monitoring as any slight changes in the position of the counter-piece could lead to some unpredictable local changes of the test conditions. This supports the use of our in situ monitoring system which allows investigating the tribological behaviour, in particular the evolution of the contact area, without test interruption and so without perturbation.

In Fig. 9, at $8 \mathrm{~h}$, a jump of the contact area of about $1 \%$ is observed. Then, the augmentation of the contact area increases linearly as the test progresses. The jump in the contact area is, at first view surprising, as the maximum load is constant at $250 \mathrm{kN}$. However, for the step starting at $8 \mathrm{~h}$, the minimum load has been increased from $1 \mathrm{kN}$ to $4 \mathrm{kN}$. This rise of the minimum load makes the lubrication of the surface more difficult, in particular when the axis rotates at its highest load $(250 \mathrm{kN})$ and cycle rate ( 9500 cycles/ $\mathrm{h})$. This difference in lubrication conditions pushes the system toward the boundary regime on a typical Stribeck curve. In other words, the system tends to a more solid-solid contacts which could lead to an increase of the contact area as observed with our optical system. Moreover, a significant increase of the temperature is measured on the cast iron counter-piece during the first $4 \mathrm{~h}$ of each new step reaching between 45 and $50{ }^{\circ} \mathrm{C}$ and staying more or less constant until the end of each step. As the temperature is measured on the cast iron counter-piece, a few millimetres away from the contact, the oil temperature in the contact area is expected to be even several degrees higher. Under such circumstances, the oil viscosity decreases so that the tribo-pair moves towards the 


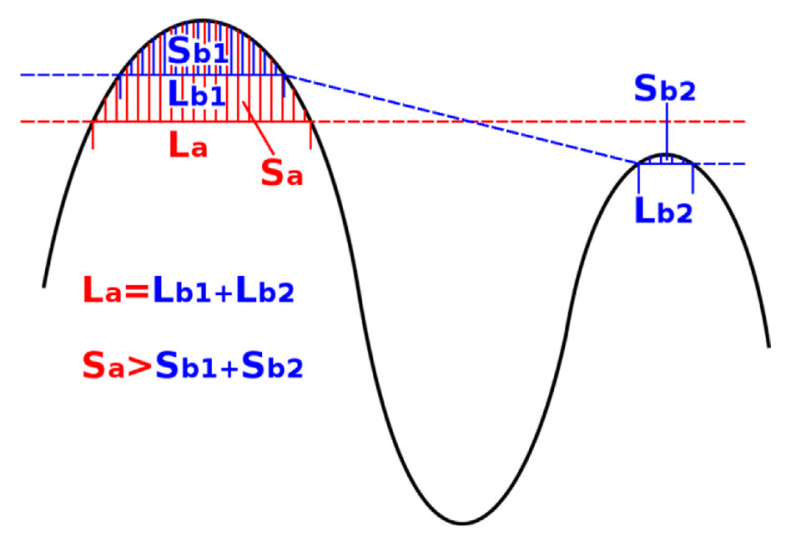

Fig. 11. Schematic representation of the wear of two asperities shown in 2D. Case a) represents the traditional way of assuming that the highest asperity is worn out before the lowest. Case b) represents the scenario observed in this study where some minor wear occurs also on the lowest asperity. For both cases, the contact length $(L)$ is the same but it can be seen that the traditional way overestimate the wear surface $(S)$, thus leading to an overestimation of the wear rate. (For interpretation of the references to color in this figure, the reader is referred to the web version of this article).

boundary conditions on the stribeck curve. These two effects, in conjunction with small mispositioning of the counter-piece after ex situ measurements, explain the relatively sharp increase of the contact area observed at the beginning of each step such as at 8, 22 and $36 \mathrm{~h}$ in Fig. 9. In this case, in the contrary to the first $4 \mathrm{~h}$ of running-in, this increase of contact area is not combined with a decrease of the coefficient of friction but with an increase. Actually, this rise of the coefficient of friction is consistent with a move to the left towards the boundary conditions on the stribeck curve [18]. Finally, after $10 \mathrm{~h}$, except for the jumps in the contact area due to the error in the positioning of the cast iron counter-piece, the increase in the contact area reaches a steady-state which indicates that the running-in is finished.

\subsection{Determination of the wear rate}

It is not possible to obtain the full topographic information just by analysing the pictures taken in situ. A topographical measurement is the additional information required. By combining the information taken in situ with the topographical measurement, the evolution of the wear rate with time can be calculated. This is the best solution as the profilometric measurement can be carried out before starting the test to get the initial surface topography. Then, no interruption of the test is necessary to have access to the evolution of the contact area since it is obtained directly from the in situ pictures. Hence, to calculate the wear rate, the AbottFirestone curve has to be obtained first from the profilometric measurement carried out ideally before starting the sliding. Fig. 10a is the Abbott-Firestone curve of the initial surface of the sample shown in Fig. 9 based on the profilometric map of the surface. It also includes the detail of the highest region and the integral lost for a $4 \%$ contact area fraction. In a second step, the volume worn out is calculated for each contact area shown in Fig. 9. To do so, it is assumed that the highest asperities are worn out during sliding. Although, this assumption is not entirely correct, it tends to overestimate the wear volume as (i) the asperities can deform plastically to create flat top without losing material and (ii) not only the highest asperities are worn out as illustrated schematically in Fig. 11. This figure represents the wear of two asperities in 2D. The first case (red line) represents the theoretical case when the highest asperity is worn out before the lowest. The second case (blue line) represents the scenario observed in this study where some minor wear occurs also on the lowest asperity. In both cases, the contact
$(L)$ has the same length but the ideal case overestimates the wear surface $(S)$, thus leading to an overestimation of the wear rate. In $3 \mathrm{D}$, the overestimation is even bigger as the case depict in Fig. 11 occurs in all directions.

The wear volume using the theoretical assumption that the highest peaks are worn out first is given by:

$V_{\text {lost }}=S_{\text {tot }} \int_{\text {hmax }}^{h} f(h) d h$

where $V_{\text {lost }}$ is the wear volume, $S_{\text {tot }}$ is the surface of the contact area, $h_{\max }$ is the height of the highest asperities, $f(h)$ is the AbbottFirestone function of the sample and $h$ is the height of the surface that provides the desired area fraction as shown in Fig. 10a. For each contact area fraction measured with our system, the corresponding height for which this fraction area is achieved is determined using the Abbott-Firestone curve. Once the wear volume is known, the wear rate is simply obtained by dividing the wear volume by the sliding distance $[19,20]$.

Based on the procedure described, the wear rate was calculated for each data point in Fig. 9 and the result is shown in Fig. 10b. From this figure, it is seen that the wear rate decreases sharply during the running-in of the tribo-system (approximately the first $10 \mathrm{~h}$ of sliding). As already mentioned, this is due to an increase of the contact surface leading to a decrease of the local pressure. Also, the decrease in the wear rate is not continuous due to the presence of some plateaus followed by sharp drops as seen at more or less $2.5,5$ and $8 \mathrm{~h}$ in Fig. 10b. This behaviour can be explained by the load and cycle variations taking place during the loading procedure (the first $8 \mathrm{~h}$ ) which impact directly the wear rate [19]. After $10 \mathrm{~h}$, apart from small jumps visible at the beginning of the steps when the cast iron counter-piece was dismounted, the wear rate decreases almost linearly to reach a steady-state regime as the test progresses. Finally, it is found that the wear rate is almost 40 times higher at the very beginning of the process as compared to the steady-state regime (after $10 \mathrm{~h}$ ). This high wear rate is due to a combination of 2 factors; high local pressure on the highest asperities and a relatively low cycle rate (4000 cycles/h). The first factor leads to a high wear volume at the beginning of the test whereas the second factor results to a smaller sliding distance than for 9500 cycles/h.

\section{Conclusion}

A simple, fast, and low-cost method was presented to monitor in situ and in real time the evolution of surface topography and estimates the corresponding sliding wear rate. This is achieved by combining an optical method with image analysis. The method was validated by analysing panoramic pictures taken during wear tests of hardened steel against grey cast iron under mixed lubricated, reciprocating conditions.

The method proposed has four additional advantages. First, it can be easily realized on real industrial tests conditions. Then, the wear rate of a complex tribo-system can be monitored in real time. Third, no interruption of the test is required which avoid the problem of sample repositioning when ex situ methods are used. Lastly, this method provides information about the real contact area, information difficult if not impossible, to obtain only by topographical analysis.

In this study, we demonstrated that the use of a collimated incident light normal to the surface as optical method is sufficient to characterise the evolution of the topographical changes (especially the contact area). By combining the information of the contact area and the Abbott-Firestone curve obtained by profilometry, the wear rate can be estimated in real time.

We demonstrated that the polished area corresponds to high local peaks of the profiles. We could also prove that if a region contains no high peaks, some low lying peaks come in contact as a 
consequence of the elastic deformation of the cast iron piece occurring during the test.

Finally, for our specific complex tribo-system, we found that the wear rate is 40 times higher in the early stage of sliding as compared to the steady-state and that the running-in was approximately $10 \mathrm{~h}$.

\section{Acknowledgements}

The authors would like to thank the Swiss Commission for Technology and Innovation (CTI - Project no. 12358.1 PFIW-IW) and the industrial partners for the financial support of this work. Special thanks to Dr. Sergio Graca for his assistance in the early stage of this work. Thanks also to Francis Pilloud for the design and construction of the optical system.

\section{References}

[1] W. Wang, P.L. Wong, Z. Zhang, Experimental study of the real time change in surface roughness during running-in for PEHL contacts, Wear 244 (2000) 140-146, http://dx.doi.org/10.1016/S0043-1648(00)00448-8.

[2] J.A. Greenwood, J.B. Williams, Contact of nominally flat surfaces, Proc. R. Soc. Lond. Ser. A 295 (1966) 300.

[3] Y.R. Jeng, Z.W. Lin, S.H. Shyu, Changes of surface topography during running-in process, J. Tribol. Trans. ASME 126 (2004) 620-625.

[4] R. Ismail, M. Tauviqirrahman, Jamari, D.J. Schipper, Topographical change of engineering surface due to running-in of rolling contacts, in: Taher Ghrib (Ed.), New Tribological Ways, InTech, http://dx.doi.org/10.5772/15408, ISBN: 978953-307-206-7http://www.intechopen.com/books/new-tribological-ways/ topographical-change-of-engineering-surface-due-to-running-in-of-rollingcontacts.

[5] P. Pawlus, Change of cylinder surface topography in the initial stage of engine life, Wear 209 (1997) 69-83, http://dx.doi.org/10.1016/S0043-1648(97)00007-0.
[6] W. Wang, P.L. Wong, J.B. Luo, Z. Zhang, A new optical technique for roughness measurement on moving surface, Tribol. Int. 31 (1998) 281-287, http://dx.doi. org/10.1016/S0301-679X(98)00034-6.

[7] W.G. Sawyer, K.J. Wahl, Accessing inaccessible interfaces: in situ approaches to materials tribology, MRS 33 (2008) 1145-1150, http://dx.doi.org/10.1557/ mrs2008.244.

[8] F. Grün, W. Sailer, I. Godor, Visualization of the processes taking place in the contact zone with in-situ tribometry, Tribol. Int. (2012), http://dx.doi.org/ 10.1016/j.triboint.2011.03.026.

[9] M. Scherge, K. Pöhlmann, A. Gervé, Wear measurement using radionuclidetechnique (RNT), Wear 254 (2003) 801-817, http://dx.doi.org/10.1016/ S0043-1648(03)00230-8.

[10] I.O. Konstantinov, N.N. Krasnov, Determination of the wear of machine parts by charged particle surface activation, J. Radioanal. Chem. 8 (1971) 357-371.

[11] U. Persson, Measurement of surface roughness on rough machined surfaces using spectral speckle correlation and image analysis, Wear 160 (1993) 221-225, http://dx.doi.org/10.1016/0043-1648(93)90424-K.

[12] G.A. Al-Kindia, B. Shirinzadeh, Evaluation of surface roughness parameters measurement using vision-based data, Int. J. Mach. Tools Manuf. 47 (2007) 697-708, http://dx.doi.org/10.1016/j.ijmachtools.2006.04.013.

[13] M.B. Kiran, B. Ramamoorthy, V. Radhakrishnan, Evaluation of surface roughness by vision system, Int. J. Mach. Tools Manuf. 38 (1998) 685-690, http://dx. doi.org/10.1016/S0890-6955(97)00118-1.

[14] C.A. Schneider, W.S. Rasband, K.W. Eliceiri, NIH Image to ImageJ: 25 years of image analysis, Nat. Methods 9 (2012) 671-675.

[15] P. Thévenaz, U.E. Ruttimann, M. Unser, A pyramid approach to subpixel registration based on intensity, IEEE Trans. Image Process. 7 (1998) 27-41.

[16] F. Saeidi, B. Meylan, P. Hoffmann, K. Wasmer, Effect of surface texturing on cast iron reciprocating against steel under starved lubrication conditions: a parametric study, Wear 348-349 (2016) 17-26.

[17] T.W. Ridler, S. Calvard, Picture thresholding using an iterative selection method, IEEE Trans. Syst. Man Cybern. 8 (1978) 630-632.

[18] L. Xiao, B.G. Rosen, N. Amini, P.H. Nilsson, A study on the effect of surface topography on rough friction, in roller contact, Wear 254 (2003) 1162-1169.

[19] J.F. Archard, Contact and rubbing of flat surfaces, J. Appl. Phys. (1953), http: //dx.doi.org/10.1063/1.1721448.

[20] L.J. Yang, Wear coefficient equation for aluminium-based matrix composites against steel disc, Wear 255 (2003) 579-592, http://dx.doi.org/10.1016 S0043-1648(03)00191-1. 